No post-mortem examination was possible until the next day, when the following changes were found.

Lungs. -The right lung was studded with caseous tuberculous masses, some an inch in diameter. There were pleural adhesions at both apices.

H cart. -Weight 7 oz. No macroscopic changes were seen.

Liccr and Pancreas.-No naked-eye changes were seen, but subsequent microscopic examination of the pancreas showed extensive fibrosis in which no islet tissue was visible. Other ductless glands showed no changes.

Gilycogen Contents. - The amount of glycogen was determined in the heart, liver, and muscles by Pflüger's method rather more than twelve hours after death had taken place. Considering the glycogenolysis that must have taken place in this time and the fact that he was a severe diabetic, the figures of 0.014 per cent. for muscle, of 0.028 per cent. for myocardium, and of 0.04 per cent. for liver are perhaps suggestive of what happens to circulating glucose in insulin hypoglycaemia.

Brain.-This was definitely "wet"; the pia mater showed areas of milkiness, but there was no evidence of basal meningitis.

In making this record of the two cases I am greatly indebted to my colleague, Dr. L. Cunningham, with whom all the biochemical work was done; also to my late housephysician, Dr. A. J. Hawe, who made many of the observations in the fatal case.

Liefman and Stern: Biochempremences

1960, 299. 2 Maclean, H., and Zeit. Physiol. Chem., 1910-11, 70, 291. \& Foster, G. L. 14, 103. 3 Frank, E. : 1923, 55, 291-303. 3 Pemberton, H. S., and Cunningham, L.: Lancet, September 27th, 1924, 647. B Mann and Magath : Amer. Journ. Physiol., 921, 4, 285. T'Steinbrinck, W. Elin. Woch, 1924, 3, 23, 1029 . ${ }^{3}$ and ${ }^{9}$ Quoted by McGuignan and Ross, loc. cit. ${ }^{10}$ McGuignan, H., and Ross, E. L.: Journ. Biol. Chem., 1915, 22, 417. 11 Bailey, C. V., and Mackay, A. : Arch, Int Med., 1920, 25, 646. ${ }^{12}$ Joslin, E. P.: Treatment oiabetes Mellitus, 1924, 620 . 13 Fatta, W. : Quoted by Cammidge Gcosuria and Allied. Conditions, 1913, 144. 14 Biery and Malloizel Quoted by McGuignan and Ross, loc.. bit. 17 Cammidge, P. J., and Howard, H. A. H. : New Vieurs on Diabetes Mellitus, 1923, 85. 18 Underhill, F. P. : Journ. Bioi. Chem., 1916, 25, 447. 19 Cammidge and Howard: Loc. cit., p. 87. 20 Underhill, F. P.: :Journ. Biol. Chem., 1916, 25, 463. 21. Quoted by Dubin, H. E., and Corbitt, H. B.: Journ. Motab. Research, 1923, 4, 89. 2: Dubin and Corbitt L Loc. cit. ${ }_{23}$ Banting, F. G., Campbell, W. R., and Fletcher, A. A. - BRitisH MEDICAL JOURNAL, January 6th, 1923, p. 8. 2: Sevringhaus, E. L., Kirk, E., and Heath, H. J.: Amer. Journ. Med. 26 Olmsted, J. M. D and Logan, H. D. : Amer. Journ. Physiol., 1923, 66. 437. 27 Dickson, B. R., Eadie, G.'S., Macleod, J. J. R., and Pember, F' R6, Quart. Journ. Exper. Physiol., April, 1924, 123. 28 Macleod, J. J. K. Loc. cit.

\section{CONGENITAL CYSTIC DISEASE OF THE LUNGS.} BY

SYDNEY SMITH, M.D., D.P.H., PRINCIPAL MEDICO-LEGAL EXPERT, EGYPTIAN GOVERNMENT.

A NEwLY born child was found dead in circumstances which suggested infanticide, and was submitted to me for examination.

The body was that of a child of about eight months' intrauterine age. It was free from marks of violence. Both lungs were in an apparently foetal condition and sank on being placed in water; both were in a state of advanced cystic degeneration (Fig. 1).

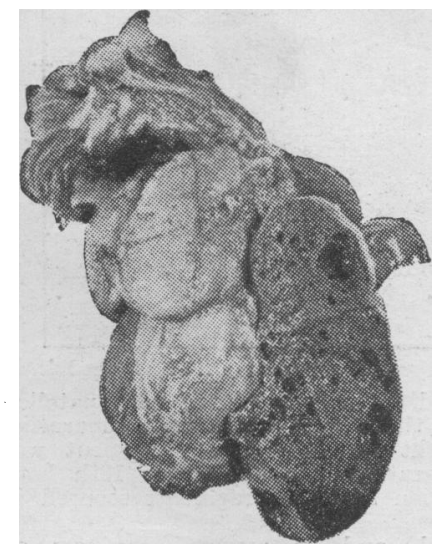

FIG. Left Lung. Cysts varying in size from a pea to the head of a pin were distributed throughout the whole of the lung tissue. The larger cysts were found towards the free surface. A number of cysts abutted on the pleura, but there were no pleural adhesions.

On microscopical examination no air cells or vesicles could be made out, the lungs being composed of unexpanded tissue and cysts. The cysts tissue and cysts. The cysts were smooth-walled and lined
in certain cases with flattened cells. There was no trace of cubical epithelium lining the cavities nor of muscular or elastic fibres in the walls. Here and there the cavities were filled with a mucoid- or colloid - looking material. Numbers of microscopic cysts could be observed immediately under the pleural surface. Numerous bronchi were seen filled with cast-off cubical and cylindrical epithelium and other debris. A certain amount of cellular infiltration could be observed around the bronchi and there were numerous small haemorrhagic foci th the lung tissue.

Cystic degeneration in both lungs of a newly born child is very rare, and the reason for its occurrence is rather obscure. Bronchiectasis occurring after birth is usually attributed to weakening of the walls of the bronchi by disease, whereby they are unable to resist the air pressure in fits of coughing. Barty King considers that pleural adhesions also play an important part in producing the initial dilatation.

In this case air pressure cannot be considered, for the child had never breathed, nor were there any pleural adhesions, and the cause of the condition must be sought elsewhere.

In the developing lung the bronchioles terminate in a bulbous extremity into which groups of atria open. Groups of air cells or alveoli which form the air sacs open into these atria. The alveoli are not formed until about the sixth month of intrauterine life, and before respiration commences they are lined with cubical epithelium which gradually becomes flattened when respiration occurs.

In our specimen the microscopical state of the tissues indicates that the cysts have not been recently formed, and their origin from the alveoli cannot be admitted in view of the late development of the alveoli. They must therefore be due to dilatation of the atria, infundibula, or bronchioles.

The absence of columnar or cubical epithelium in even the smallest cysts and of any trace of muscular or elastic tissue in their walls tends to exclude an origin from bronchi or bronchioles. Such a condition is, however, found in ordinary bronchiectasis, where the pressure of the retained secretion causes flattening of the cubical or cylindrical epithelium, while the stretching causes atrophy and disappearance of the muscular fibres. It would be difficult, therefore, to be certain from the histological disposition of the tissues whether we are dealing with a dilated bronchus or a dilated infundibulum, but the appearance of the smaller cysts particularly does not resemble bronchial dilatation. The cysts are found immediately under the pleura, and as the terminations of the bronchioles do not abut on the pleural surface this tends to exclude an infundibular origin. The condition is therefore a congenital cystic degeneration of both lungs caused by the dilatation of the atria.

The presence of mucoid or colloid matter in many of the cysts indicates that secretion from their walls is fairly active, and if, as is suggested by the microscopical sections, there was some inflammation of the bronchioles which caused blocking of their lumen, this would account for the retention of the secretion and dilatation from the consequent pressure.

\section{PNEUMOCOCCAL WOUND INFECTION :} Notes on Two Cases.

BY

\section{BERTRAM MUIR, M.B., B.S., F.R.C.S.,}

HONORARY SURGEON, SHANTUNG ROAD HOSPITAL, SHANGHAT.

CASEs of suppuration due to the pneumococcus in regions other than the upper and lower respiratory tracts and adjacent sinuses, the pericardium and peritoneum, the meninges, and the middle ear, are sufficiently rare to merit publication, especially when the infection is apparently primary and not blood-borne. Even the subcutaneous injection of a virulent pneumococcal culture in guinea-pigs causes death by septicaemia, with comparatively little local reaction, although a local abseess, with a characteristic fibrinous exudate, sometimes forms. The two cases here described were both "traversing" bullet wounds, and in both the primary infection appeared to be pneumococcal.

\section{CaSe I.-Pncumococcal Infection of Diffuse Traumatic Aneurysm} of the Axilla.

A Chinese soldier, aged 35, was shot through the right sab clavicular region in November, 1924. The bullet entered anteriorly and traversed the pectoralis major, injured the third part of the andlary artery, and passed out through the teres major muscle. A tense pulsating swelling immediately formed in the right axilla, A tense pulsating swelling immediately formed in the right axilla, and he lost the use of the right hand, although no sensory diseither wound. After a few weeks the swelling increased so much that he had to maintain the arm in a position of marked abduction.

Six weeks later the swelling became very painful, and the 
overlying skin brawny-red and hot, and for the first time he felt ill and presented himself for treatment. When admitted the temperature was $103^{\circ}$ and the right radial pulse was practically absent; from the clinical signs of the axillary swelling a diagnosis of diffuse aneurysm of the axillary artery was made. As it was obviously infected and seemed liable to rupture at any moment, surgical treatment was urgent.

\section{Operation.}

On January 18th I ligatured the third part of the right subclavian as a preliminary step, and then explored the axillary swelling. A longitudinal incision was made along the course of the artery, the pectoral tendons were incised, and a thick fibrous sac revealed, formed by the inere incised, and a thick fibrous sac revealed, formed by the incorporated axillary fascia and costocoracoid membrane anteriorly. This was incised, and yellow
purulent fibrinous clot turned out. Brisk haemorrhage occurred purulent fibrinous clot turned out. Brisk haemorrhage occurred
from a hole in the third part of the artery, on the inner and lower aspect, which appeared to be the result of the original injury. The axillary vein and nerves were matted together in the outer wall of the sac, but eventually I succeeded in ligaturing the vessel above and below the openings, and the haemorrhage ceased. The remaining purulent clot was turned out, the pectoral tendons remaining purulent clot was turned out, the pectoral tendons showed a pure pneumococcal growth.

Two days later it became evident that infection had spread along the course of the brachial artery to the antecubital fossa and along the ulnar nerve to the olecranon process. The abscesses were incised at these points and drained; culture again yielded pneumococci. The patient made a slow but uneventful convalescence.

\section{CASE II.-Pncumococcal Infection of Left Supraclavicular Region.}

A Chinaman received a revolver bullet in the left supraclavicular region on February 21st and was admitted to hospiial three days later. A small round wound through the clavicular head of the left sterno-mastoid, just above the clavicle, was discharging pus. A skiagram showed the bullet to be lodged in front of the neck of the first rib.

\section{Operation.}

On February 28th I turned back an angular supraclavicular flap and explored the left subclavian triangle. The bullet was found lying on the neck of the first rib, between the fibres of the scalenus medius and longus colli muscles, beneath the lower fibres of the brachial plexus. The pleural dome and lung apex were lininjured. The bullet was removed without difficulty and drainage established. Three days later the temperature rose to $103^{\circ}$, and a reddened fluctuating swelling was observed in the delto-pectoral region. On incision this was found to extend deeply to the axillary sheath, and a quantity of yellow fibrinous pus was evacuated, which on culture yielded pneumococci. The patient made an uneventful convalescence.

These cases are only of scientific interest from the infection standpoint, as pneumococcal infection of wounds is very rare; indeed, $I$ can find no recorded cases in a fairly extensive perusal of current medical literature. Both lesions were in the vicinity of the thorax, but even in Case II there was no lesion of the lung or pleura. Possibly the infection was from the patient's clothing, which in each case had been traversed by the bullet and was filthy. Another interesting fact was that infection spread along the vascular sheath in each case, without any marked local reaction after operation. In each case drainage and eusol irrigation proved a satisfactory method of treatment for the secondary abscesses.

\section{Atemoramda:}

\section{MEDICAL, SURGICAL, OBSTETRICAL. PERFORATION OF THE JEJUNUM DURING AN ATTACK OF LOBAR PNEUMONIA: \\ LAPAROTOMY : RECOVERY.}

Perforation of the jejunum (apart from injury) is an exceedingly rare condition; I can find no record of a case similar to that about to be described.

Mr. B. B., aged 24, had a "chronic appendix " removed through a gridiron incision in April, 1923. He made a rapid convalescence, and remained in perfect health until November, 1924, when he was seized with acute pains in the chest. The condition was diagnosed and treated as lobar pneumonia. The right lung was consolidated, and his temperature, after remaining consistently consolidated, and his temperature, after remaining consistently seventh day after the onset of his illness he had severe abdominal pains, the abdomen became distended, and vomiting was a trouble some feature. He had intractable diarrhoea, although previously he was constipated. I examined the patient three days after the beginning of the abdominal symptoms. He was acutely ill, semidelirious, and emaciated. The temperature was then $101^{\circ} \mathrm{F}$ pulse 120 , respirations 32 . There were signs of consolidation of he right lower lobe of his lung. The abdomen was ballooned, inmobile, rigid, tender, and tympanitic. The area of liver dullness was not appreciably diminished, and shifting dullness could be detected in the flanks. As the abdominal muscles were on guard, no mass or viscus could be palpated. Apart from some tenderness of the pelvic peritoneum no other abnormality could be detected of the pelvic peritone

\section{operation.}

Although the patient seemed moribund immediate coeliotomy was decided upon. He was anaesthetized with gas and ether, and $6 \mathrm{c.cm}$. of stovaine (light solution) was injected into the lumbar spinal theca. The abdomen was explored through a right paramedian incision which displaced the rectus muscle outwards. On opening the peritoneal cavity a large quantity of gas and darkbrown fluid escaped through the a large quantity of gas and darkwere bathed in fluid, and the intestines grossly distended and glued together in places, the exploration was conducted under the greatest difficulties. The stomach, duodenum, and gall bladder were normal, but about 12 inches from the duodeno-jejunal flexure a circular perforation, a quarter of an inch in diameter and surrounded by a narrow strip of yellow necrotic tissue, was found on the ante-mesenteric border of the distended jejumum. There was no evidence of any induration or scarring around the perforated zone which would be suggestive of a previous chronic ulcerated condition of the gut. The breach in the jejunum was invaginated by two purse-string sutures of fine catgut and a protective omental pad applied to the site. About 6 inches further down the gut there was a circular gangrenous patch which was similarly invaginated and guarded with an omental pad. After this procedure no further examinations of the intestine were possible owing to the patient's critical condition and after providing for drainage of the pelvis and right lliac fossa, the abdominal wound was closed in three layers.

The patient rallied splendidly after the operation. He was able to return home and resume light work five weeks after the exploration. When seen some three months after the operation he reported himself as being quite fit and sound.

It is to be presumed that the gangrenous patch in the jejunum and the perforation were due to septic infarcts; yet it is interesting to note that there was no evidence of infarction elsewhere.

Rodney Maingot, F.R.C.S. Surgeon, Royal Waterloo Hospital, London.

\section{FRACTURE OF BOTH PATELLAE BY MUSCULAR ACTION.}

The following case is thought worthy of record. The patient was under the care of Dr. R. S. Dickson of Palmer's Green, at whose request I operated, and to whom I am indebted for the following notes.

R. C. male, aged 20, was admitted to the Passmore Edwards Hospital, Wood Green, on September 8th, 1923, with the history that while playing tennis on that date " he had jumped upwards suddenly between 2 ared 3 feet to take a high ball at the net," when something snapped in both knees and he fell to the ground.

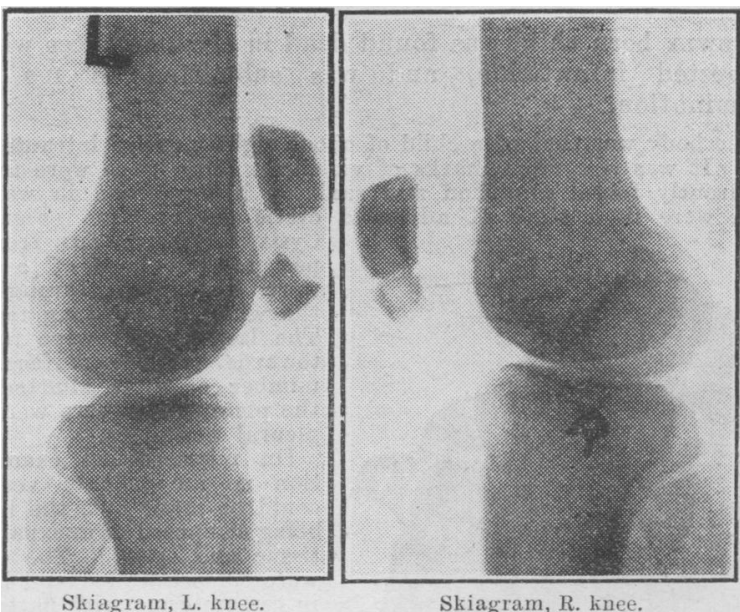

On examination he was found to have fractured both patellae transversely. On the left side there was considerable separation of the fragments. On the right side the lower fragment was small, and there was less separation. On September 18th both knees were subjected to operation and the fragments secured in apposition with silver wire.

Convalescence was uneventful, and he resumed business on November 15th, 1923.

That both patellae should give way, as in this case, must be unusual. We were unable to find any evidence of abnormality in the osseous system. The patient was an exceedingly athletic and well developed young man, with a sound family and medical history. Moreover, the bones at operation were quite normal in texture.

London, $\mathbf{W}$

T. Twistington Higgins, F.R.C.S. 